\title{
Isoflurane use is not associated with prolonged intensive care unit stay following routine cardiac surgery when compared to sevoflurane
}

\author{
Michael Charlesworth, MSc $\cdot$ Alan Ashworth, MBChB, FRCA • \\ Sarah Stirling, MBChB, FRCA
}

Received: 19 August 2016/Revised: 31 August 2016/Accepted: 12 October 2016/Published online: 25 October 2016

(C) Canadian Anesthesiologists' Society 2016

\section{To the Editor,}

We wish to comment on the article in which Jones et al. compared the clinical outcomes of patients undergoing routine coronary artery or single heart valve surgery prospectively randomized to either sevoflurane or isoflurane for maintenance of anesthesia. ${ }^{1}$ We congratulate the authors on producing a high quality pragmatic trial that has real-world practice implications.

Sevoflurane is not routinely used for cardiac surgery in the United Kingdom, whereas isoflurane vaporizers continue to occupy a prominent position in our cardiac operating theatres. The reasons for this are mainly cost related as low-flow anesthesia is not always possible. In addition, flow while on-bypass is somewhat higher than the $2 \mathrm{~L} \cdot \mathrm{min}^{-1}$ average described by the authors for costcalculation purposes. Thus, the study findings show-much to our relief - that we are likely doing the right thing for our patients in a time of economic challenge. In addition, isoflurane has the advantage of being less polluting with regard to global warming. ${ }^{2}$

There were several aspects of their report that we would like to address. First, the minimum alveolar concentration (MAC) ranges they reported were very wide - wider than we would generally employ in regular clinical practice for these procedures - albeit the comparative MAC values for

This letter is accompanied by a reply. Please see Can J Anesth 2017; 64: this issue.

M. Charlesworth, MSc $(\bowtie) \cdot A$. Ashworth, MBChB, FRCA S. Stirling, MBChB, FRCA

Department of Cardiothoracic Anaesthesia, Critical Care and ECMO-University Hospital of South Manchester, Manchester, UK

e-mail: mda05mc@gmail.com each group demonstrated that both drugs were used in an equivalent manner.

Second, we find in our own hospital that discharge from the intensive care unit (ICU) to the ward is often delayed because of logistical issues. Therefore, we see the use of the outcome of prolonged ICU stay as somewhat problematic.

Lastly, we found it a bit confusing to see the pooling of the two outcomes (i.e., 30-day all-cause mortality and prolonged ICU stay) as the primary study outcome because each had been considered separately as secondary outcomes. Fig. 2 from Jones et al. shows that these outcomes have very different relative risks and confidence intervals. Furthermore, they most likely have very different causes and subsequent consequences for the patient. Because of the low overall incidence of 30-day allcause mortality $(1.9 \%)$ compared with the much higher overall incidence of prolonged ICU stay $(26.7 \%)$, the composite primary outcome $(28.7 \%)$ is largely a reflection of the prolonged ICU stay. Considering these data, it is perhaps possible to say that there is good evidence for there being no difference with regard to prolonged ICU stay or some of the other secondary outcomes (i.e., use of inotropes/vasopressors, incidence of new-onset atrial fibrillation). It is, however, more difficult to say it of 30day all-cause mortality because of its low overall incidence and the resultant wide confidence interval.

This study demonstrates the equivalence of two volatile agents for routine cardiac surgery with regard to clinically important outcomes. Studies that demonstrate no statistical significance between two treatments are often criticized for being underpowered. These criticisms regarding power, however, have been widely debated. ${ }^{3}$ In the Jones et al. study, the sample size was calculated a priori to have a 
power of $80 \%$ to show that the true difference in the event rate was $<10 \%$ using a true primary outcome incidence of $25 \%$. This seems entirely reasonable for the outcome regarding prolonged ICU stay. However, the baseline incidence of 30-day all-cause mortality is significantly lower. Hence, if it were to be considered separately, a much larger study would be required. Whether such a study would be worthwhile pragmatically is debatable. For now, though, we will undoubtedly continue with our routine use of isoflurane for cardiac surgery.

Funding No funding received.

Competing interests None declared.
Editorial responsibility This submission was handled by Dr. Hilary P. Grocott, Editor-in-Chief, Canadian Journal of Anesthesia.

\section{References}

1. Jones PM, Bainbridge D, Chu MW, et al. Comparison of isoflurane and sevoflurane in cardiac surgery: a randomized non-inferiority comparative effectiveness trial. Can J Anesth 2016. DOI:10.1007/ s12630-016-0706-y.

2. Charlesworth M. How green is your gas? AAGBI Anaesthesia News 2009; 267: 21-2.

3. Hoenig JM, Heisey DM. The abuse of power: the pervasive fallacy of power calculations for data analysis. Am Stat 2001; 55: 19-24. 